\title{
Construction of Front-end Set and Delivery System Based on Robot Goods Sorting Operation
}

\author{
Yi Hui, Yajing Yang, Xin Fan \\ Department of Graduate, Beijing Wuzi University, Beijing, China
}

Email address:

huiy25@126.com (Yi Hui),455622438@qq.com (Yajing Yang),310794845@qq.com (Xin Fan)

To cite this article:

Yi Hui, Yajing Yang, Xin Fan. Construction of Front-end Set and Delivery System Based on Robot Goods Sorting Operation. Science Research. Vol. 4, No. 5, 2016, pp. 141-145. doi: 10.11648/j.sr.20160405.16

Received: November 24, 2016; Accepted: December 6, 2016; Published: December 16, 2016

\begin{abstract}
This paper introduce a new method to realize the set and delivery of the goods by changing speed on the conveyor belt, and the machine control several servo motors by PLC. By adjusting the speed of the servo motors, the speed difference between the conveyor belts realize the separate of goods steady and provide the convenience for the robot. At the same time, the method of adjusting distance of the goods both save the space and reduce the cost.
\end{abstract}

Keywords: Conveyor Belt, Adjust Speed, Robot

\section{Research Background}

This paper based on robot goods sorting operation to design a front-end goods set and delivery system Goods space is adjusted by the set and delivery system to prevent the accumulation of goods caused by the operation of the robot rhythm disorders or other problems.

\section{Function and Characteristics of the Set and Delivery System}

The goal of the front-end system is mainly to achieve the separation of the equal space between the goods and the speed control to ensure that the goods arrive at the sorting module can achieve the $2 \mathrm{~m} / \mathrm{s}$ running speed to meet the high-speed sorting requirements.

In order to make each link work effectively, the distance between the belts and the sorting performance of the robot is needed. If the transport capacity is less than the sorting ability, the efficiency of sorting will be affected. Adjusting the system to make the same distance between goods can solve this problem effectively. The traditional control method is realized by setting up a quantitative counting mechanism, a storage buffer technique, or a mechanical device which is matched with the conveying belt. The traditional methods have some limitations. Therefore, the system plans to use a new method to adjust the distance.

\section{The Construction of the Set and Delivery System}

The system uses PLC to control the servo motor, the entire set and delivery system control several servo motor by the PLC, servo motor in the role of PLC control motor speed. Through the design of a flexible control distribution system to facilitate the robot's sorting work, when the goods through the set and delivery module, the module will increase the speed of the conveyor belt to maintain a speed difference between the two adjacent conveyor belts. And the speed difference between the two adjacent conveyor belts will make distance between goods. At the same time, we can control the goods separation distance by designing the speed of several conveyor belts to make the goods transportation at the same distance. As shown in figure 1:

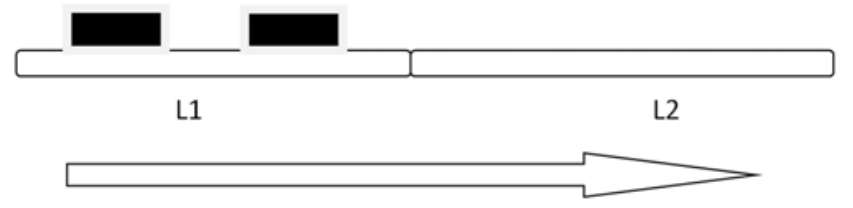

Figure 1. Sketch map of decentralized control.

The belt speed change from left to right by setting. For example: $\mathrm{V}_{\mathrm{L} 1}<\mathrm{V}_{\mathrm{L} 2}$. Once a goods movement from the previous conveyor belt to next conveyor belt, because of the 
speed change, the effect of friction will make the goods have an acceleration to realize the separation between goods, then we can design the belt through the number and speed to achieve the required.

Assuming that the entire transmission device is composed of six conveyor belts from left to right, and the belt speed become quicker from left to right. That is: $\mathrm{V}_{\mathrm{L} 1}<\mathrm{V}_{\mathrm{L} 2}<\mathrm{V}_{\mathrm{L} 3}<$
$\mathrm{V}_{\mathrm{L} 4}<\mathrm{V}_{\mathrm{L} 5}<\mathrm{V}_{\mathrm{L} 6}$. Making research of the relationship between the distance, conveyor belt speed difference and other factors, in order to achieve the calculated spacing distance can be determined according to the external factors, and we need to determine the target distance to complete the requirements with the numbers of conveyor belts. As shown in figureure 2:

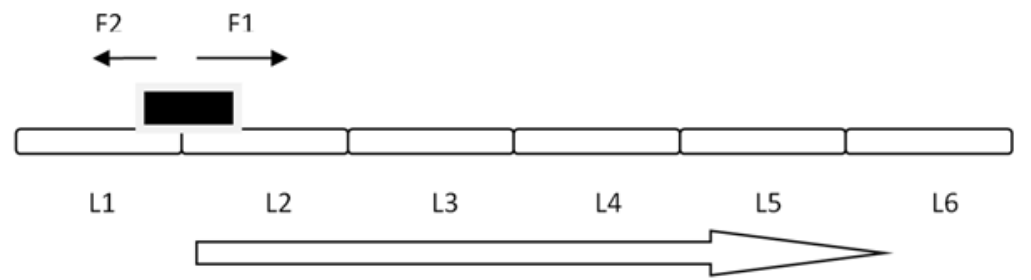

Figure 2. Sketch map of decentralized control.

The main control unit use PLC to realize the goods separation of the set and delivery system, and the controlled elements is the servo motor of each conveyor belt, the servo motors run by the control of PLC. At the same time, the servo motor can achieve the function of speed adjustment. And because of the function of the servo motor, the running speed of the conveyor belt can be obtained at any time according to the specific needs of the workshop, thus increasing the overall flexibility of the set and delivery system. The structure diagram is shown in figureure 3 .

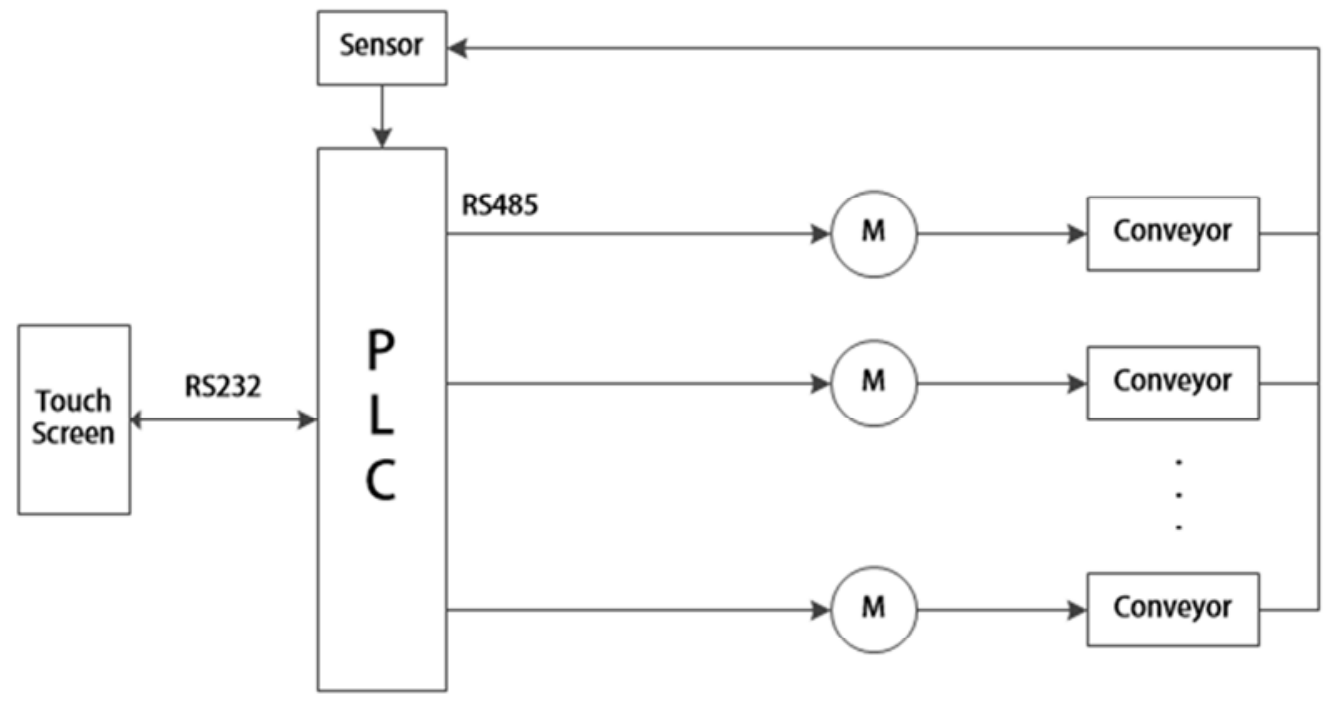

Figure 3. The structure diagram.

\section{The Establishment and Analysis of Spacing Control Model}

To make the goods separation by two conveyor belts, we mainly through the three time period to complete:

1 The speed of precious conveyor belt is $V_{1}$, and the speed of the next is $\mathrm{V}_{2}$. The goods which the quality is $\mathrm{M}$ and the tangent length with the conveyor belt is $\mathrm{L}$ will make a accelerated speed movement between conveyor belts, when the static friction $F_{1}$ which is forward is bigger than the dynamic friction $F_{2}$ which is rearwards, goods will produce a forward acceleration. Supposed that the acceleration is a, and we assume a critical point when $\mathrm{F}_{1}=\mathrm{F}_{2}(\mathrm{a}=0)$. A variable $\mathrm{x}$ is a displacement distance between the two conveyor belts when the acceleration $=0$, the $0<\mathrm{x}<\mathrm{h}$ ( $\mathrm{h}$ is the total distance from the critical point to the previous conveyor belt). According to Newton's second law:

$$
\mathrm{F}_{1}-\mathrm{F}_{2}=\mathrm{ma}=\frac{x}{L} \mathrm{~g} \mu \mathrm{m}, \mathrm{a}=\frac{x}{L} \mathrm{~g} \mu
$$

We can find that $\mathrm{x}$ will continue to grow in the process of goods movement, and the acceleration of the goods will continue to change with the continuous bigger of $x$. It is a continuous process of $\mathrm{X}$ change from 0 to $\mathrm{h}$, and we assume that the belt speed is $V_{h}$ when the goods leave the conveyor completely $\left(\mathrm{V}_{1}<\mathrm{V}_{\mathrm{h}}<\mathrm{V}_{2}\right)$, according to the principle of calculus, the $V_{t}$ is the speed of the goods run time $t$ from the critical point $\left(\mathrm{V}_{1} \leq \mathrm{V}_{\mathrm{t}} \leq \mathrm{V}_{\mathrm{h}}\right)$, we can know: 


$$
\mathrm{Vt}-\mathrm{V}_{1}=\int_{0}^{\mathrm{t}}\left(\frac{\mathrm{x}}{\mathrm{L}} \mu \mathrm{g}\right) \mathrm{dx}=\frac{\mu \mathrm{gt}^{2}}{2 \mathrm{~L}}
$$

At this time, $\mathrm{D}_{\mathrm{t}}$ is the distance when the goods begin to run from the critical point:

$$
D t=\int_{0}^{t}\left(V_{x}-V_{1}\right) d x=\int_{0}^{t}\left(\frac{\mu g x^{2}}{2 L}\right) d x=\frac{\mu g t^{3}}{6 L}
$$

When the $\mathrm{Dt}=\mathrm{h}$, the goods has just left the previous belt, we can know the running time $t_{h}$ :

$$
t_{h}=\sqrt[3]{\frac{6 h L}{\mu g}}
$$

At this time we can find, the move distance of goods 2 in the time of th is V1th, So the distance between two adjacent goods L1 and L2 in this period is:

$$
\mathrm{h}_{1}-\mathrm{V}_{1} \mathrm{t}_{\mathrm{h} 1}=\mathrm{h}_{1}-\mathrm{V}_{1} \sqrt[3]{\frac{6 \mathrm{~h}_{1} \mathrm{~L}_{1}}{\mu_{1} \mathrm{~g}}}
$$

$\mathrm{h}_{1}$ : The total distance of goods 1 from the critical point to the previous conveyor belt before leaving.

$\mathrm{V}_{1}$ : The speed at the previous conveyor belt.

$t_{h 1}$ : The running time of goods 1 from the critical point to the previous conveyor belt before leaving.

L1: The total length of the goods 1 contact with the conveyor belt belt

$\mu_{1}$ : Coefficient of friction between goods 1 and conveyor

2 When goods 1 leave the previous conveyor belt, goods 1 will follow the conveyor belt at the speed of V2 forward, at this time the former goods 2 will experience the process from the previous conveyor belt accelerate to the next conveyor belt, we assume that the total tangent length between the goods 2 and the conveyor belt is $\mathrm{L}_{2}$, the total distance from critical point to the time when goods don't touch the first conveyor is $\mathrm{h}_{2}$. According to the last formula, the $\mathrm{T}_{\mathrm{h} 2}$ which is the running time of second goods from the critical point to the first conveyor belt before leaving.

$$
\mathrm{T}_{\mathrm{h} 2}=\sqrt[3]{\frac{6 \mathrm{~h}_{2} \mathrm{~L}_{2}}{\mu_{2} \mathrm{~g}}}
$$

So the distance between two adjacent goods L1 and L2 in this time of $\mathrm{T}_{\mathrm{h} 2}$ is:

$$
\mathrm{V}_{2} \mathrm{th}_{2}-\mathrm{h}_{2}=\mathrm{V}_{2} \sqrt[3]{\frac{6 \mathrm{~h}_{2} \mathrm{~L}_{2}}{\mu_{2} \mathrm{~g}}}-\mathrm{h}_{2}
$$

$\mathrm{V}_{2}$ : The speed of the former conveyor belt

$\mathrm{h}_{2}$ : The total distance of goods 2 from the critical point to the previous conveyor belt before leaving.

$\mathrm{L}_{2}$ : The total length of the goods 2 contact with the conveyor belt

$\mu_{2}$ : Coefficient of friction between goods 2 and conveyor belt

3 In the time of goods 2 from touching next conveyor belt just now to the accelerated speed critical point, goods 1 move at the speed of $V_{2}$, and the goods 2 move at the speed of $V_{1}$, During this time, It will make some distance between goods 1 and goods 2 , the time of this running process is $\frac{\mathrm{L}_{2}-\mathrm{h}_{2}}{\mathrm{~V}_{1}}$, And the distance between the goods 2 and the goods 1 is in this period of time is:

$$
\left(\frac{\mathrm{L}_{2}-\mathrm{h}_{2}}{\mathrm{~V}_{1}}\right)\left(\mathrm{V}_{2}-\mathrm{V}_{1}\right)
$$

In summary, when two goods pass the two segment of the transmission belt, the distance is:

$$
\left(\frac{\mathrm{L}_{2}-\mathrm{h}_{2}}{\mathrm{v}_{1}}\right)\left(\mathrm{V}_{2}-\mathrm{V}_{1}\right)+\mathrm{h}_{1}-\mathrm{V}_{1} \sqrt[3]{\frac{6 \mathrm{~h}_{1} \mathrm{~L}_{1}}{\mu_{1} \mathrm{~g}}}+\mathrm{V}_{2} \sqrt[3]{\frac{6 \mathrm{~h}_{2} \mathrm{~L}_{2}}{\mu_{2} \mathrm{~g}}}-\mathrm{h}_{2}
$$

The same as: $\frac{\left(\mathrm{L}_{2}-\mathrm{h}_{2}\right) \mathrm{V}_{2}}{\mathrm{~V}_{1}}+\mathrm{h}_{1}+\mathrm{V}_{2} \sqrt[3]{\frac{6 \mathrm{~h}_{2} \mathrm{~L}_{2}}{\mu_{2} \mathrm{~g}}}-\mathrm{V}_{1} \sqrt[3]{\frac{6 \mathrm{~h}_{1} \mathrm{~L}_{1}}{\mu_{1} \mathrm{~g}}}-\mathrm{L}_{2}$

$\mathrm{g}$ : Acceleration of gravity

Therefore, through the above formula, when we know the tangent length between goods and belt is L, the distance from the time of acceleration is zero to the time of the maximum acceleration is $\mathrm{h}$, the coefficient of friction between good and conveyor belt is $\mu$, the speed $V_{1}$ of the previous belt and the speed $\mathrm{V}_{2}$ of the former belt, we can determine transmission process between the two belt and we can know the distance of the adjacent goods.

\section{System Programming and Design}

\subsection{Hardware Selection}

Multi section discrete automatic control system is realized through PLC combined with servo motor control, we achieve the difference of the conveyor belt by the control of the servo motor.

According to the actual set and delivery system, the system choose the DVP10MC11T PLC

The PLC related parameters are as follows:

1. communication interface: RS485

2. encoder interface: to provide $24 \mathrm{~V}$ and $5 \mathrm{~V}$ voltage output, for the encoder to use; A, B phase difference input, the maximum frequency of $1 \mathrm{MHZ}$

3. I/0 system: 8 channel high speed interrupt input point $\mathrm{X} 0-7$; 4 channel high speed corresponding output point $\mathrm{Y} 0-3$

The belt speed of the set and delivery system is no more than $2 \mathrm{~m} / \mathrm{s}$, according to the experience we choose the servo system ASDA0423-M, the servo system ASDA-M have some advantages: each axis provide $6 \mathrm{D}$ and $3 \mathrm{DO}$; there are $18 \mathrm{DI}$ and 9 DO totally. At the same time, ASDA-M combine three servo motor in one machine and three axis control, data exchange between axes, no time delay. Software has a simple circular analysis function and it can strengthen the ability of diagnosis system.

\subsection{Program Design}

Multi band discrete automatic control system is realized through PLC combined with servo motor control, through the servo motor speed control to achieve the speed of the transmission belt different, and then produce the speed 
difference. The system sends the control signal to control multiple servo motor through the delta PLC, by setting the servo motor to set the belt speed, the specific procedures are as follows:

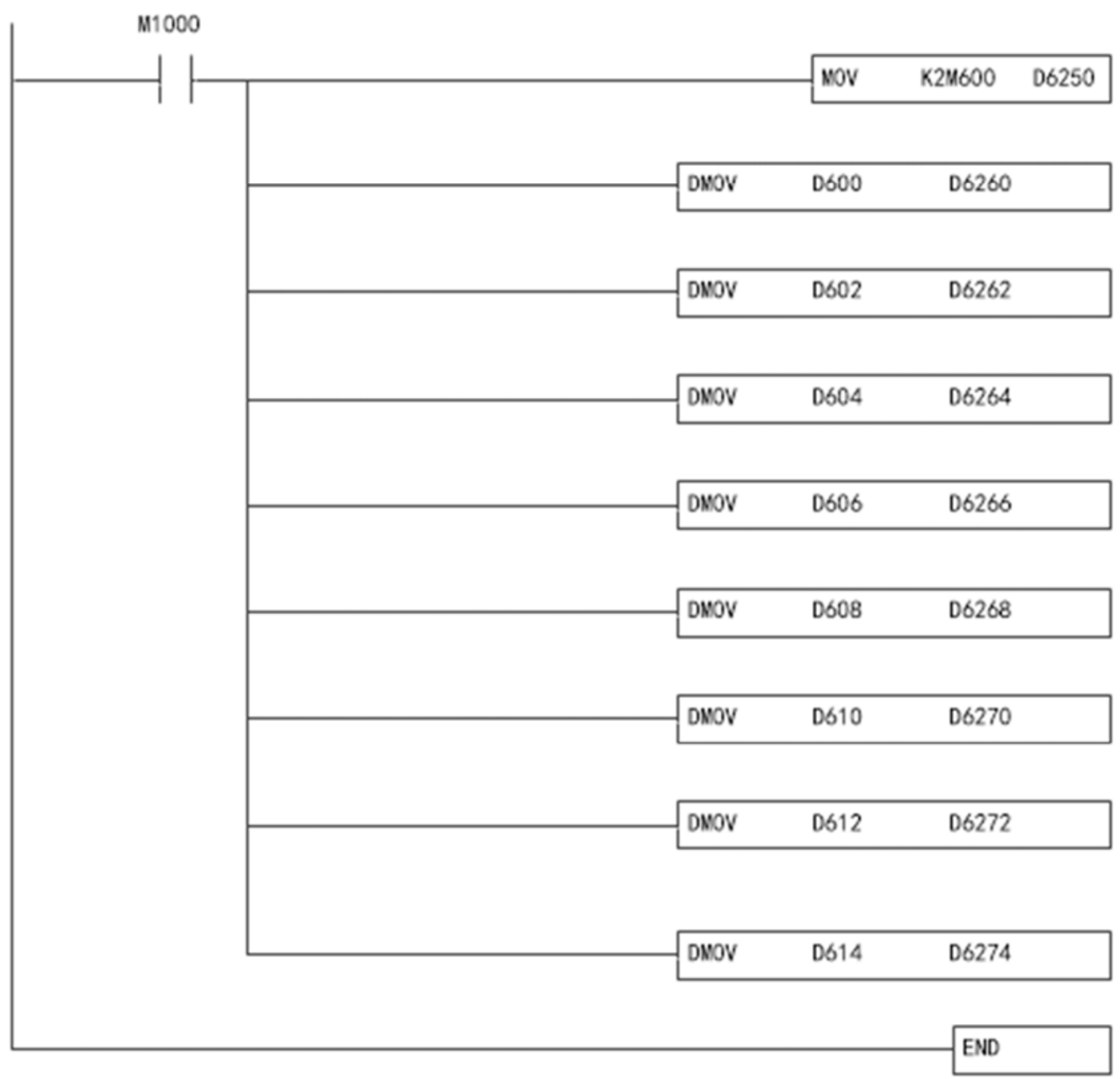

Figure 4. The program of servo motor to control the speed of the conveyor belt.

\section{Summary}

The main content of this paper is to establish the belt discrete control system, we can know object separation distance depends on the conveyor belt between the system through modeling and analyzing the differential size and other factor, the system have a small separation of the large distance estimates by determining the speed difference of objects, and provides a theoretical basis for the robot the starting point of grasping distance. At the same time, through the system analysis to the actual operation of the program control system controlled by PLC servo motor speed control of belt transmission, which increases the flexibility of the speed control can improve the stability of the system. Finally, the experimental results show that it can solve the problem of the accumulation of goods effectively, and provide convenience for the subsequent robot sorting system.

\section{Acknowledgements}

This paper is based on Beijing Wuzi University Graduate Innovation and Entrepreneurship Project, item number: 0541605843 .

\section{References}

[1] Yan Yi-Qing, Pan Li-Ping, Automatic sorting system based on PLC Mechanical and electrical engineering 2012 (11).

[2] George A, Weimer I. V. New robotics technology adds value to material handling $[\mathrm{J}]$, pallerizing Material Handling Engineering 1998, 53 (7): 61-65.

[3] Ming Xie. Robot Vision: A Holistic View [J]. International Conference on Climbing and Walking Robots. 2004.

[4] Milan Sonka, Vaclav Hiavac. Roger Boyle [J]. Image Processing, Analysis, and Machine Vision. 2001. 
[5] Belongie S, Malik J, Puzicha J. Shape matching and object recognition using shape contexts [J]. IEEE Transactions on Pattern Analysis and Machine Intelligence. 2002.

[6] S Belongie, J Malik, J Puzicha Matching Shapes [J]. IC-CV2001. 2001.

[7] Echelmeyer W, Kirchheim A, Wellbrock E. Robotics-Logistics Challenges for Automation of Logistic Processes [J]. IEEE International Conference on Automation and Logistics, 2008 Sept 1-3.
[8] Philip Kotler. Marketing Management [M], USA: Prentic-Hall, Inc, 2000.

[9] Clyde E Witt, Forspeed or reliability, automatic palletizers are the right choice [J], Material Handing Engeering, 1996, 51 (4): 13-20.

[10] Clyde E Witt, Palletizing unit load: many options [J], Material Handling Engeering, 199954 (1): 99-106. 